Original Article

\title{
THE IMPORTANCE OF ANTIBIOTICS IN A VARIOUS UNIQUE METASTASIS ALONG WITH CYTOTOXIC THERAPY AT TERTIARY CARE HOSPITAL: A PROSPECTIVE COHORT STUDY
}

\author{
G. SAI KIRAN, N. DOONDI PHANI KUMAR*
}

The Institution: Nirmala College of Pharmacy

Email: phani.krishna.07.97@gmail.com

Received: 20 Mar 2020, Revised and Accepted: 22 May 2020

\section{ABSTRACT}

Objective: Rare cancers are creating a massive challenge to the world. It has associated with genetic mutations or socio-environmental factors, which includes genes, smoking, alcohol, ionizing radiation exposure, organic-inorganic chemicals, air and water pollution, viruses, and bacteria. When 15 cases per 1,00,000 people per year, we can consider it as a rare case as per the National Cancer Institute

This study aim is the importance of antibiotics in various unique metastasis along with cytotoxic therapy at tertiary care hospital.

Methods: The inclusion criteria of our study include a person who is suffering from rare metastasis at an early stage. We excluded the data that are those who are suffering from the typical type of cancers, multiple co-morbid conditions. This study was carried out the Prospective Cohort Study conducted between June 2018 to March 2020.

Results: Number of 20 rare cancers we consider for final analysis, the overall antibiotics use in this study 18 antibiotics they prescribed in overall cases, prescribed cytotoxic drugs are 23. the chi-square test value is $\mathrm{P}=0.001$, the confidence interval(CI) is $95 \%$, the likelihood ratio is 54.4 , odd's ratio is $2.0(\mathrm{CI} 95 \%, \mathrm{P}=0.711$ ), Male patients more than the female patients.

Conclusion: Cancer is a complex disorder, which is occurred through gene proliferation and socio-environmental factors. Rare metastasis is challenging to physicians and patients, however as per our observation, cytotoxic therapy with antibiotics can reduce the risk of rare metastasis and as well improved therapeutic adhesion, and we need clear supporting evidence on it through clinical trials.

Keywords: Rare cancers, Cytotoxic therapy, Antibiotic utilization

(C) 2020 The Authors. Published by Innovare Academic Sciences Pvt Ltd. This is an open access article under the CC BY license (http://creativecommons.org/licenses/by/4.0/) DOI: http://dx.doi.org/10.22159/ijcpr.2020v12i4.39048. Journal homepage: https://innovareacademics.in/journals/index.php/ijcpr

\section{INTRODUCTION}

Cancers is a complicative disorder. Rare cancers are creating a massive challenge to the world [1], generally associated with genetic mutations or socio-environmental factors, which includes genes, smoking, alcohol, ionizing radiation exposure, organic-inorganic chemicals, air and water pollution, viruses, and bacteria [2]. Some organizations entrusted are there to provide comprehensive care to patients and improve the life expectancy of the survivors [3]. Each type of cancer has a specific biomarker observed in the body; for example, Burkitt's lymphoma occurs due to over expression of an MYC-c [4]. The Cancer mortality rate in India has doubled from 1990 to 2016 [5]. India's cancer incidence estimated that 1.1million new patients in 2018, and prognosticate to almost doubled up as a result of demographic transitions alone by 2040 [6]. Rare metastasis is a unique nature, which is a challenge to the physicians and their patients to diagnose their patients to prevent the disease. When 15 cases per 1,00,000 people per year, we can consider it as a rare case as per the National Cancer Institute [7].

Moreover, various cytotoxic therapies are available for different kinds of metastasis [8]. Often observed cytotoxic side effects such as nausea, vomiting, alopecia, gastrointestinal disturbances [9]. During the cytotoxic therapy, physicians prescribe antibiotics, antivirals [10], antifungal [11]. However, Physicians prescribe antibiotics based on the patient's immune system, condition, severity, and etiological factors considered. Most of the Chemotherapy protocols are decreasing the white blood cells(WBC), which fight against microbiota [12]. If we are prescribing antibiotics continuously to a patient may get antibiotic resistance, which is the world's biggest problem and WBC cells unable to fight against microbes [13]. It is profoundly impacting the therapeutic adhesion and as well typical to handle the infection condition if it may develop.

\section{MATERIALS AND METHODS}

\section{Study design}

This study was carried out the Prospective Cohort Study conducted between June 2018 to March 2020. At the Department of Oncology, Manipal super speciality hospital, Tadepalli, Vijayawada, Andhra Pradesh.

Data Collected from the oncology ward. We have received around 2000 different types of oncology cases that excluded the data that are those who are suffering from the typical type of cancers, multiple co-morbid conditions. The inclusion criteria of our study include a person who is suffering from rare metastasis at an early stage. We evaluated that cancer cases utilization of antibiotics, along with the treatment. We divided into two antibiotics exposure groups and non-exposure groups; we consider as group one is an antibiotic exposure group with rare cancers, and group 2 is a non-exposure group; it means non-antibiotics exposure.

\section{Statistic considerations}

We collected unique cancer cases, and the collected rare metastasis data extracted analysed from Statistical Package for The Social Sciences (SPSS-ver-26). The statistical approach of the study is Descriptive statistics, Chi-square test, correlation, ANOVA, odds ratio (OR).

\section{RESULTS}

The data shows that rare cancer cases are recorded $(\mathrm{N}=20)$, table 1 describes the gender distribution that represents male patients $(\mathrm{N}=14)$ are more than Female patients $(\mathrm{N}=6)$. Most of the rare cancers are observed in male patients. The most common type of chief complaint is fever(3 15\%); later on, abdominal pain (2 10\%) in figure-1we can be observed. 
Table 1: Gender distribution

\begin{tabular}{lll}
\hline Gender & Frequency & Percent \\
\hline $\mathrm{F}$ & 6 & 18.2 \\
$\mathrm{M}$ & 14 & 42.4 \\
\hline
\end{tabular}

Table 2 describes the descriptive statistics of each parameter we take. The mean and standard error mean (SEM) of each parameter as follows age $43.65 \pm 5.208(\mathrm{~N}=20)$, Hemoglobin $9.5 \pm 0.56(\mathrm{~N}=18)$, Creatinine $0.75 \pm 0.74(\mathrm{~N}=11)$, Total bilirubin $0.67 \pm 0.25(\mathrm{~N}=10)$
Direct bilirubin $0.33 \pm 0.139(\mathrm{~N}=10)$, Indirect bilirubin $0.34 \pm 0.37$, SGOT $41 \pm 15(\mathrm{~N}=10)$, SGPT $41 \pm 15(\mathrm{~N}=10)$, platelet count $203266 \pm 49218(\mathrm{~N}=15)$, white blood cells $6607 \pm 1092(\mathrm{~N}=14)$ respectively.

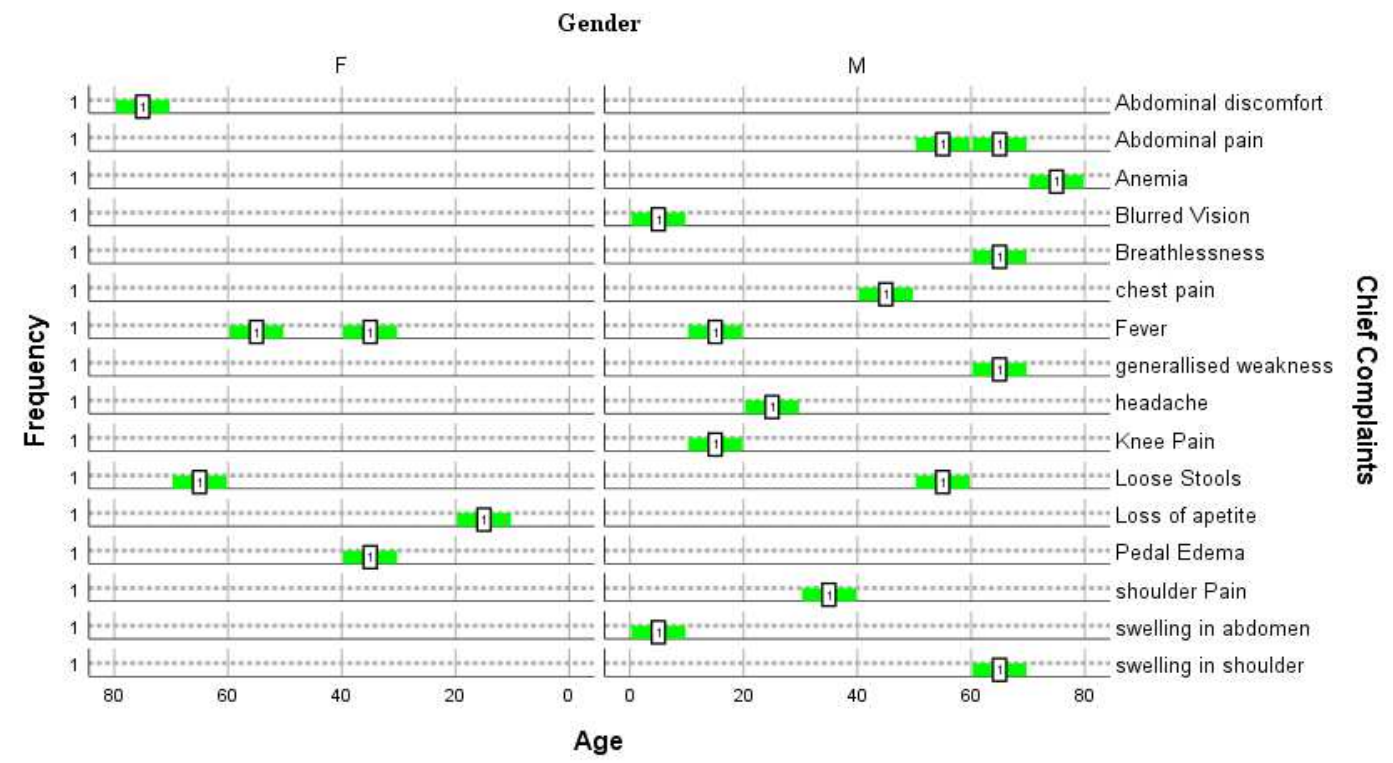

Fig. 1: The histogram describes gender. vs. age. vs. frequency of chief complaints

During the study period we observed very unique characteristics of each individuals, those are Pancreatic carcinoma(15\%), Acute myeloid leukemia(15\%), Burkitt's lymphoma(10\%), Wilms tumor(5\%), Soft tissue sarcoma(5\%), stomach cancer(5\%), Hepatoblastoma (5\%),
Retinoblastoma (5\%), Mediastinal tumor(5\%), Relapsed multiple myeloma(5\%), Medulloblastoma(5\%), osteosarcoma(5\%), ovary carcinoma(5\%). The fig. 2 describes the how many patients are suffering from different type unique metastasis.

Table 2: Descriptive statistics of each parameter

\begin{tabular}{|c|c|c|c|c|c|c|c|c|}
\hline \multirow[t]{2}{*}{ Parameters } & \multirow{2}{*}{$\begin{array}{l}\mathbf{N} \\
\text { Statistic } \\
\end{array}$} & \multicolumn{2}{|l|}{ Mean } & \multirow{2}{*}{$\begin{array}{l}\text { Std. deviation } \\
\text { Statistic }\end{array}$} & \multirow{2}{*}{$\begin{array}{l}\text { Variance } \\
\text { Statistic } \\
\end{array}$} & \multirow{2}{*}{$\begin{array}{l}\text { Skewness } \\
\text { Statistic } \\
\end{array}$} & & \multirow[t]{2}{*}{$\mathbf{F}$} \\
\hline & & Statistic & Std. error & & & & Std. error & \\
\hline Age & 20 & 43.65 & 5.208 & 23.293 & 542.555 & -.453 & .512 & 2.312 \\
\hline Creatinine & 11 & .7527 & .07470 & .24775 & .061 & 1.226 & .661 & 0.435 \\
\hline Direct Bilirubin & 10 & .3340 & .13946 & .44101 & .194 & 2.895 & .687 & 0.001 \\
\hline Hemoglobin & 18 & 9.5722 & .56446 & 2.39480 & 5.735 & .360 & .536 & 0.582 \\
\hline Indirect & 10 & .3340 & .11798 & .37310 & .139 & 2.254 & .687 & 0.001 \\
\hline \multicolumn{9}{|l|}{ Bilirubin } \\
\hline Platelet count & 15 & 203266.6667 & 49218.49504 & 190622.41161 & 36336903809.524 & .816 & .580 & 0.001 \\
\hline SGOT & 10 & 41.4000 & 15.90891 & 50.30838 & 2530.933 & 2.305 & .687 & 0.121 \\
\hline SGPT & 10 & 26.5000 & 5.46555 & 17.28358 & 298.722 & 1.401 & .687 & 3.374 \\
\hline Total Bilirubin & 10 & .6740 & .25213 & .79729 & .636 & 2.757 & .687 & 118 \\
\hline WBC & 14 & 6607.1429 & 1092.10273 & 4086.27426 & 16697637.363 & .251 & .597 & 100 \\
\hline
\end{tabular}

Table 3a explains the prescribed cytotoxic drugs while in treatment most wildly used drug is vincristine(4 12.1\%), Carboplatin (2 6.1\%), cisplatin (2 6.1\%), cytarabine(2 6.1\%), Zoledronic acid(2 6.1\%), Decitabine(1 3\%), Dexamethasone(1 3\%), Doxorubicin(1 3\%), etoposide(1 3\%), $\quad$ Folfirinox(1 3\%), $\quad$ ifosfamide(1 3\%), Methotrexate(1 3\%), octreotide acetate(1 3\%), rituximab(1 3\%).

Table $3 \mathrm{~b}$ describes the antibiotic utilization while in the treatment mostly used antibiotics are Acyclovir (4 12.1\%), meropenem
(2 6.1\%), sulfamethoxazole trimethoprim (2 6.1\%), voriconazole(2 6.1\%), Actinomycin (1 3.0\%), Amikacin $(1 \sim 3.0 \%)$, fluconazole $(1 \sim 3.0 \%)$, metronidazole (1 3.0\%), polymyxin $\quad \mathrm{E}(1 \sim 3.0 \%)$, tigecycline $(1 \sim 3.0 \%)$, vancomycin (1 3.0\%). The chi-square test value is 119 ( $D F=12, P=0.001)$, the confidence interval (CI) is $95 \%$, the likelihood ratio is 54.4 , odd's ratio is $2.0(\mathrm{CI} 95 \%, \mathrm{P}=0.711$ ) (if odds ratio $>1$ that exposure is an only group one). 


\section{Diagnosis}

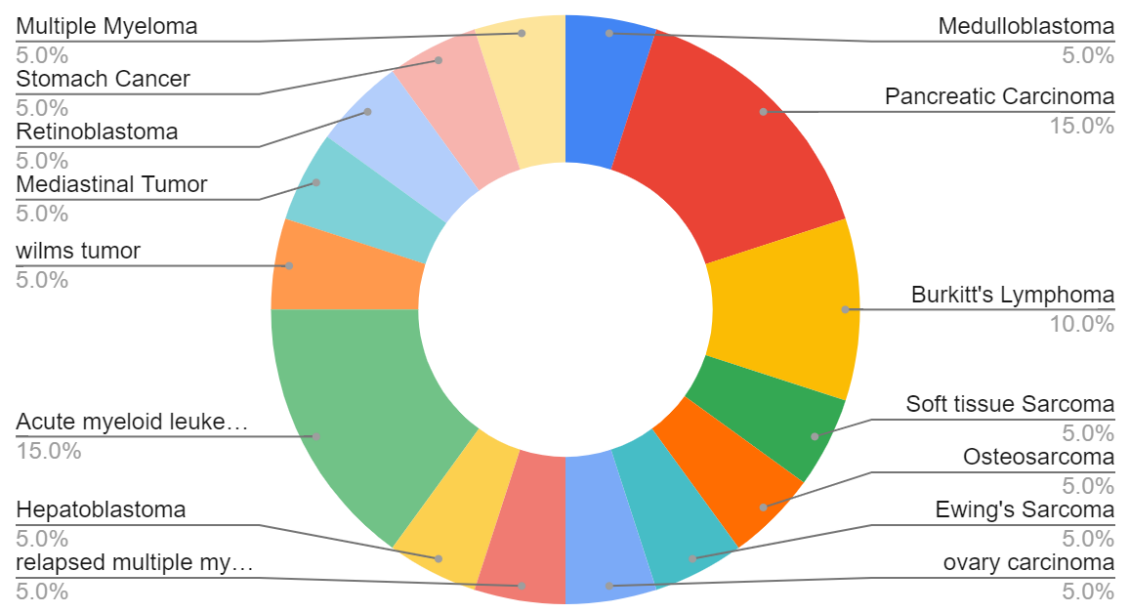

Fig. 2: Observed individual diagnosis

Table 3a: Chemotherapy prescribed drugs in various kind of unique carcinomas

\begin{tabular}{lll}
\hline Name of the drugs & Frequency & Percent \\
\hline Carboplatin & 2 & 6.1 \\
Cisplatin & 2 & 6.1 \\
cytarabine & 2 & 6.1 \\
Decitabine & 1 & 3.0 \\
Dexamethasone & 1 & 3.0 \\
Doxorubicin & 1 & 3.0 \\
Etoposide & 1 & 3.0 \\
Folfirinox & 1 & 3.0 \\
ifosfamide & 2 & 3.0 \\
Methotrexate & 1 & 3.0 \\
octreotide acetate & 1 & 3.0 \\
Rituximab & 1 & 3.0 \\
vincristine & 4 & 12.1 \\
Zoledronic acid & 2 & 6.1 \\
\hline
\end{tabular}

Table 3b: Antibiotic utilization in chemotherapy

\begin{tabular}{lll}
\hline Name of the drugs & Frequency & Percent \\
\hline Actinomycin & 1 & 3.0 \\
Acyclovir & 4 & 12.1 \\
Amikacin & 1 & 3.0 \\
Fluconazole & 1 & 3.0 \\
Meropenem & 2 & 6.1 \\
Metronidazole & 1 & 3.0 \\
Piperacillin+Tazobactam & 1 & 3.0 \\
polymyxin E & 1 & 3.0 \\
Sulfamethoxazole+Trimethoprim & 2 & 6.1 \\
Tigecycline & 1 & 3.0 \\
Vancomycin & 1 & 3.0 \\
Voriconazole & 2 & 6.1 \\
\hline
\end{tabular}

As per the chis square value this study is exstremely siginificant $(\mathrm{P}<0.001)$

\section{DISCUSSION}

This study result shows that antibiotic utilization during ongoing cytotoxic treatment of rare metastasis. The antibiotics prescribed in the only particular specific conditions like pancreatic carcinoma, Burkitt's lymphoma, Ewing's sarcoma, Wilms tumour, Hepatoblastoma, Acute myeloid leukaemia. However, in pancreatic carcinoma, antibiotics are decreasing tumour proliferation by $50 \%$ studied in animal models [14]. Burkitt's lymphoma occurs in three conditions like Epstein bar virus, sporadic and immunodeficiency associated diseases such as HIV condition, the use of antivirals in this condition EBV and HIV decrease the risk of secondary infection condition $[15,16]$. In Ewings sarcoma, it often occurs in around the bones they prescribed RNA synthesis inhibitors [17]. Wilms tumour antibiotic usage is very less than comparing other types of carcinomas because of the immature form of cells developed when the baby was born [18]. Likewise,every metastasis having hidden challenges is furthermore investigation needs in clinical trials.

\section{CONCLUSION}

Cancer is a complex disorder, which is occurred through gene proliferation and socio-environmental factors. Rare metastasis is challenging to physicians and patients, however, cytotoxic therapy with antibiotics can reduce the risk of rare metastasis and as well improved therapeutic adhesion,and we need clear supporting evidence on it through clinical trials. 


\section{FUNDING}

No organization come forward to do this work

\section{AUTHORS CONTRIBUTIONS}

All the authors have contributed equally.

\section{CONFLICT OF INTERESTS}

Declare none

\section{REFERENCES}

1. Pillai RK, Jayasree K. Rare cancers: challenges and issues. Indian J Med Res 2017;145:17.

2. Parsa N. Environmental factors inducing human cancers. Iran J Public Health 2012;41:1-9.

3. Gospodarowicz M, Trypuc J, Cruz AD, Khader J, Omar S, Knaul F. Cancer services and the comprehensive cancer center. Third Edition. Vol, 3. Disease Control Priorities; 2015. p. 195.

4. Schmitz R, Ceribelli M, Pittaluga S, Wright G, Staudt LM. Oncogenic mechanisms in Burkitt lymphoma. Cold Spring Harb Perspect Med 2014;4:a014282.

5. Dhillon PK, Mathur P, Nandakumar A, Fitzmaurice C, Kumar GA, Mehrotra $\mathrm{R}$, et al. The burden of cancers and their variations across the states of India: the global burden of disease study 1990-2016. Lancet Oncol 2018;19:1289-306.

6. Smith RD, Mallath MK. History of the growing burden of cancer in India: from antiquity to the 21st century. J Global Oncol 2019;5:1-15.

7. DeSantis CE, Kramer JL, Jemal A. The burden of rare cancers in the United States. CA: A Cancer J Clinicians 2017;67:261-72.

8. Pucci C, Martinelli C, Ciofani G. Innovative approaches for cancer treatment: current perspectives and new challenges. Ecancer Med Sci 2019;13:961.
9. Nurgali K, Jagoe RT, Abalo R. Editorial: adverse effects of cancer chemotherapy: anything new to improve tolerance and reduce sequelae? Frontiers Pharmacol 2018;9:245.

10. Alibek K, Bekmurzayeva A, Mussabekova A, Sultankulov B. Using antimicrobial adjuvant therapy in cancer treatment: a review. Infectious Agents Cancer 2012;7:33.

11. Staber P, Langner S, Dornbusch HJ, Neumeister P. Antifungal management in cancer patients. Wiener Medizinische Wochenschrift 2007;157:503-10.

12. University. MCoGaA. Antibiotics may impact cancer treatment efficacy. Sci Daily; 2018.

13. Aslam B, Wang W, Arshad MI, Khurshid M, Muzammil S, Rasool MH, et al. Antibiotic resistance: a rundown of a global crisis. Infection and drug resistance. 2018;11:164558.

14. Biocompare. Antibiotics may be key to boosting pancreatic cancer treatment. Thursday; 2018.

15. Kalisz K, Alessandrino F, Beck R, Smith D, Kikano E, Ramaiya $\mathrm{NH}$, et al. An update on burkitt lymphoma: a review of pathogenesis and multimodality imaging assessment of disease presentation, treatment response, and recurrence. Insights Into Imaging 2019;10:56.

16. Pannone G, Zamparese R, Pace M, Pedicillo MC, Cagiano S, Somma $\mathrm{P}$, et al. The role of EBV in the pathogenesis of Burkitt's Lymphoma: an Italian hospital based survey. Infectious Agents Cancer 2014;9:34.

17. Biswas B, Bakhshi S. Management of ewing sarcoma family of tumors: current scenario and unmet need. World J Orthopedics 2016;7:527-38.

18. Cancer.net. Wilms Tumor-Childhood: Introduction; 2019 https://www.cancer.net/cancer-types/wilms-tumor-childhood/ introduction [Last accessed on 20 Mar 2019] 